Le second problème est d'un autre ordre. Davidson manifeste une préférence marquée pour les théories modestes, les positions affaiblies. Mais que faut-il penser d'une théorie du langage qui, tout en reconnaissant la nature intentionnelle des langues, choisit de s'en tenir au point de vue de l'extension, ou d'une théorie de l'esprit qui admet d'emblée n'avoir «pas réussi à saisir notre concept intuitif de mental» (p. 283) ? Certes la nécessité est mère de l'invention, et Davidson exploite avec une rare ingéniosité les maigres ressources qu'il s'autorise à utiliser. Certains mettront également à son crédit l'honnêteté et la modestie intellectuelles qui font qu'il est le premier à signaler les limites ou les insuffisances de ses théories. D'autres, en revanche, s'étonneront que tant d'espoirs aient été mis dans des propositions qui semblaient se condamner par avance à l'échec et demanderont de ne pas prendre pour acquis que la politique des demi-mesures soit la mieux à même de nous rapprocher de la vérité. Heureusement, il n'est pas nécessaire d'être d'accord avec toutes les thèses défendues par l'auteur, ni d'être victime d'américanomanie, pour reconnaître qu'il s'agit d'une contribution de premier plan. Ce n'est pas d'aujourd'hui que la philosophie s'interroge sur la causalité ou sur les rapports de l'âme et du corps, et l'on aimerait lire plus souvent des ouvrages de cette qualité. Pascal Engel a joint une présentation, qui permet au lecteur de s'orienter dans les essais qui la suivent et donne un aperçu des nombreux débats qu'ils ont suscités. La traduction aurait gagné à être faite avec plus de soin et il faut trop souvent pour comprendre se rapporter à l'original. En dépit de ces négligences, auxquelles il n'aurait pas été difficile de remédier, le public francophone saura gré au traducteur de lui avoir permis de juger sur pièce de l'œuvre d'un des plus en vue parmi les philosophes du Nouveau Monde.

Michel BourdeAu

\title{
CULTURES ET HISTOIRE
}

La Rome des premiers siècles. Légende et histoire. Actes de la table ronde en l'honneur de Massimo Pallotrino, Paris, 3-4 mai 1990. Florence, Leo S. Olschki, 1992. $19 \times 27,5$, VII-270 p., index, pl. («Istituto nazionale di studi etruschi e italici. Studi etruschi », 24).

C'est un bel hommage que la Section française de l'Institut national d'études étrusques et italiques a rendu à son président Massimo Pallottino en organisant, en liaison avec le Laboratoire d'archéologie de l'École normale supérieure et l'Équipe 
"Recherches étrusco-italiques " du CNRS, une table ronde à Paris, les 3 et 4 mai 1990. Les actes donnent aux lecteurs la possibilité de disposer, dans un même volume, d'un ensemble de travaux qui témoignent de la vitalité des recherches actuelles sur la Rome des premiers siècles. Cette histoire des origines est saisie ici au cœur des rapports entre légende et histoire. Objets, dans le passé, de controverses virulentes, ils sont étudiés, dans cet ouvrage, par des approches nouvelles et fructueuses qui enrichissent les connaissances sur ces âges obscurs et nourrissent la réflexion sur l'élaboration, par les Romains, de leur histoire ainsi que sur nos propres pratiques historiques.

Quelques thèmes majeurs se dégagent de l'ensemble des communications qui touchent à la fois aux problèmes méthodologiques, historiques, idéologiques et historiographiques.

C'est, en effet, à un ensemble de réflexions méthodologiques que nous convient, en premier lieu, plusieurs auteurs; tous, s'interrogeant sur l'apport des sciences dites auxiliaires, incitent les chercheurs à une grande prudence. Il en est ainsi de l'archéologie à laquelle il est fait fréquemment appel, à juste titre, mais quelquefois de manière peut-être abusive, pour confirmer les récits de l'annalistique. On peut se demander si cette préoccupation de chercher dans l'archéologie une justification de la tradition littéraire n'interdit pas une approche plus libre et donc plus fructueuse de la documentation archéologique. Les données de l'épigraphie et de l'onomastique paraissent plus directement utilisables. On sait l'importance - même si certains points restent encore obscurs - des inscriptions de la tombe François de Vulci, pour la compréhension de la geste de Servius Tullius. L'inscription, récemment étudiée, sur un vase du musée du Louvre, faisant connaître un Laucies Mezenties, est elle aussi d'un grand intérêt puisqu'elle rend vraisemblable l'existence du roi de Caeré; il en est de même pour celles d'Avile Vipiennas gravées sur deux coupes, l'une du vi siècle, connue par les fouilles du sanctuaire de Portinaccio à Véies et l'autre, d'origine inconnue, qui date du milieu du $v^{e}$ siècle et qui se trouve au musée Rodin à Paris. Il est vraisemblable qu'il s'agit de cet Aulus Vibenna, compagnon du Macstrna de la tombe François. Mais, comme le note, sur un plan plus général, Massimo Pallottino, il importe de distinguer clairement et de manière rigoureuse ce qui est de l'ordre du véritable et de l'ordre du vraisemblable. C'est à ce prix que l'histoire de Rome archaïque continuera à progresser. C'est du reste ce dont témoignent les études qui, dans ces actes, proposent des lectures nouvelles ou renouvelées de certains passages de l'annalistique.

Qu'il s'agisse d'analyser des récits ou certaines pratiques politiques (distribution du butin, débat sur le triomphe des tribuns militaires, etc, ), c'est la même méthode qui est mise en œuvre par les chercheurs; tous s'efforcent de saisir, dans les moindres détails, les événements ou les données rapportées par la tradition littéraire afin d'en dégager le sens au plus près de ce que l'on connaît des pratiques sociales, religieuses et juridiques de ce monde si lointain et, à bien des égards, si étranger au nôtre. Ainsi, au vu de la pratique étrusque des hostiae animales et en liaison avec le modèle que semble constituer le sacrifice des prisonniers troyens offert par Achille pour les mânes de Patrocle, une analyse nouvelle est donnée du massacre, en 358, des trois cent sept captifs romains de Tarquinia; cet événement, rapporté par TiteLive (VII, 15, 9-10), peut être compris comme un sacrifice - assurément exceptionnel - qui devait permettre aux défunts de connaître une véritable divinisation. 
Ce sont aussi à des sacrifices, mais alors expiatoires et propritiatoires, que répondent apparemment les morts volontaires de Lucrèce et d'Horatius Coclès. En revanche, il semble bien que l'on soit en présence de la transformation d'un rite obscur italicoétrusque avec le célèbre épisode de l'enlèvement des Sabines : l'étude des scènes de rapt, nombreuses dans l'iconographie étrusque, et tout particulièrement sur les reliefs de Chiusi, incite à penser que c'est entre la fin du vi ${ }^{e}$ siècle et le milieu du $\mathrm{v}^{e}$ siècle que ce rite, lié aux jeux équestres et athlétiques, est devenu un récit étiologique sur les débuts de Rome. Cela dit, l'importance des jeux étrusques pour l'histoire de Rome est ici saisie par l'analyse de l'aurige de Ratumenna : si l'aventure de l'aurige de Véies, emporté par ses chevaux et renversé aux portes de Rome est symbolique, celle de la gens Ratumenna s'enracine bien dans l'histoire de Rome.

La place et la fonction des primordia romana dans l'élaboration de l'histoire même de Rome et dans le développement de l'idéologie du pouvoir constituent un thème également important. Il ne paraît pas douteux que les imperatores, dès Sylla, et peut-être même dès Marius, aient utilisé, pour renforcer leur pouvoir, l'image de Servius Tullius; l'intégration du modèle servien sera très habilement opérée par Auguste. À l'époque des Julio-Claudiens, sous d'autres formes, la fonction idéologique de Servius Tullius est aussi perceptible que la place donnée à l'Étrurie dans l'histoire de Rome. À cet égard, le bas relief des populi etrusci, dégagé à Cerveteri au $\mathrm{XIX}^{\mathrm{e}}$ siècle, apporte un témoignage du plus grand intérêt sur les rapports entre l'histoire et la politique. Le réexamen du dossier permet de suggérer, comme le pensait déjà au siècle dernier Canina, que ces reliefs, représentant de manière symbolique certains peuples étrusques, décoraient le trône qui, conçu pour recevoir les « insignia imperii », pouvait renvoyer à la proédrie des jeux et avoir sa place dans un Augusteum à Cerveteri.

Enfin, le dernier thème qui se dégage des actes de ce colloque est celui de l'histoire de la légende. Comment s'est constituée cette légende ? Quelle en est la dimension philosophique? Comment s'est établie la chronologie? Autant de questions auxquelles répondent d'importantes analyses qui associent préoccupations historiographiques et réflexions philosophiques.

La diversité des thèmes abordés, la finesse des analyses, la richesse de la documentation et la pertinence des hypothèses proposées conduisent à porter une grande attention à cet ouvrage stimulant pour la pensée, agréable à lire, à cette réserve près qu'un nombre considérable de coquilles ont échappé à l'examen des correcteurs. On le regrettera s'agissant d'un ouvrage de cette qualité.

Claire Feuvrier Prévotat

Le Sabbat des sorciers en Europe $\left(X V^{2}-X v m f^{f}\right.$ siècle). Colloque international ENS Fontenay-Saint-Cloud, 4-7 nov. 1992, textes réunis par Nicole JACQUES-Chaquin, Maxime PréAud. Grenoble, Jérôme Millon, 1993. 16 × 24, 439 p.

Les sorcières et sorciers ont donné lieu, ces dernières années, à une production historique abondante renouvelant le champ des recherches sur la sorcellerie euro- 
péenne. Le colloque consacré au sabbat par l'ENS de Fontenay-Saint-Cloud s'inscrit dans cette direction. Un de ses intérêts est de se consacrer à l'unique thème du sabbat, ce qui le distingue des publications récentes tournées vers la répression de la sorcellerie européenne ${ }^{2}$. Le thème s'inspire du dernier ouvrage paru en France de Carlo Ginsburg, Le Sabbat des sorcières (1992), auteur de l'intervention qui inaugure la première partie du colloque. Celle-ci est consacrée aux sources et à leur interprétation. Le sabbat peut être vu comme un stéréotype culturel ancien. Afin de mieux comprendre les origines culturelles du sabbat, Carlo Ginsburg propose que les historiens adoptent un regard plus anthropologique. Cela permettrait de dépasser la question, reprise dans de nombreuses communications du colloque, de savoir si le sabbat est une création des élites cultivées et si elle est différente de celle du peuple. Un fond commun est peut-être présent. On peut discerner, par exemple, des traces de vol chamanique dans l'envol des sorcières vers le sabbat et des rites préchrétiens dans le Blakulla scandinave ou dans le sabbat aragonais. Le sabbat peut aussi donner lieu à une interprétation politique. Une seule communication choisit d'aborder la représentation politique du sabbat à travers la littérature du XvII siècle. Le sabbat est alors considéré " comme une allégorie de l'impensable qui se profile avec la nouvelle institution de l'État et le nouvel individualisme sur lequel il s'appuiera " (H. Merlin).

La diversité des pratiques du sabbat fait l'objet de la seconde partie du colloque. Le champ d'étude des différentes communications est avant tout européen, malgré une intervention sur les États-Unis et une autre sur l'Amérique latine. Il permet d'ouvrir l'information historique vers des contrées peu connues des Européens de l'ouest, tels les Pays baltes, l'Europe centrale ou le Brésil. Les communications portent à la fois sur la répression du sabbat et sur son déroulement. Les sabbats européens présentent des éléments fondamentaux communs. Les sorciers et sorcières s'envolent vers un lieu de réunion où ils rendent un culte au diable. Des variantes s'imposent cependant selon les régions. Aux Canaries, par exemple, au large de l'Afrique, il n'est pas rare de voir le diable se transformer en chameau pour emporter ses serviteurs vers le lieu du sabbat. En Suède, Blakulla, la colline bleue, est le lieu national de réunion des sorciers. Il montre une image double: il est l'Enfer et le Paradis à la fois, où les anges surveillent les enfants pour les empêcher de servir le diable.

La dernière partie du colloque est consacrée à l'image du sabbat. L'originalité et l'intérêt de certaines communications résident dans le fait qu'elles délaissent les documents issus des procès pour sorcellerie (interrogatoires des accusés, des témoins et des accusateurs) et les récits de sabbat des démonologues, traditionnels champs de recherche des historiens. Elles étudient, en revanche, l'image de celui-ci à travers les documents iconographiques, longtemps négligés pour connaître la représentation du sabbat à l'époque moderne. L'utilisation de cadavres humains à des fins maléfiques, par exemple, est un thème de prédilection de l'iconographie au

2. Nous pensons à l'ouvrage de B. P. Levack, La Grande Chasse aux sorcières en Europe aux débuts des temps modernes, Paris, Champ Vallon, 1991, auquel répond celui de R. Muchembled, Le Roi et la Sorcière. L'Europe des bûchers, x $v^{\prime}$-xvmi siècle, Paris, Desclée, 1993. 
$\mathrm{XvI}^{\mathrm{e}}$ siècle. Jambes, saucisses phalliques et crânes mijotent dans les chaudrons des sorcières. Il s'agit d'une allusion à la sorcellerie comme moyen de s'approprier du pouvoir, en l'occurrence celui des hommes. L'adjonction de Saturne dans les scènes de sorcellerie liées au cannibalisme fait des sorcières les exemples vivants du pouvoir destructeur du désir sexuel. Les peintres hollandais du xvII ${ }^{\mathrm{e}}$ siècle donnent du sabbat une image différente de celle qu'on rencontre dans les manuels de démonologie et les procès. En étudiant les scènes de sabbat dans une comparaison avec les codes picturaux d'autres scènes de genre, M. Löwenstein observe que l'image des sorcières est ambivalente. Les sorcières, participantes actives du sabbat, ne sont pas seulement diaboliques. Elles personnifient aussi les péchés mortels que sont l'avarice et la luxure. La présence de sorcières âgées aux côtés des jeunes dans le sabbat souligne en outre l'aspect transitoire de la vie terrestre, un peu sur le modèle des natures mortes ou des vanités.

Une remarque vient cependant à l'esprit à la lecture des communications de ce colloque. Elle concerne la place du sabbat dans la répression de la sorcellerie abordée brièvement par quelques auteurs. Beaucoup se basent sur les archives judiciaires de l'époque moderne pour analyser le sabbat. Or celui-ci n'a pas toujours intéressé les juges. En Allemagne, il faut attendre le $\mathrm{XvII}^{\mathrm{e}}$ siècle pour que les juges se soucient véritablement des réunions nocturnes. Au moment où la chasse aux sorcières se fait plus intense, les questions se font plus précises sur le sabbat. Cependant, les juges s'intéressent plus aux aspects séculiers des assemblées de sorciers (dénonciation des complices de la conspiration) qu'à ses composantes théologiques. Les juges restent encore sceptiques vis-à-vis du sabbat. En France, le seul aveu du sabbat, preuve juridique de culpabilité de l'accusé, ne suffit pas pour faire condamner à mort par le parlement de Paris, qui finit d'ailleurs par «décriminaliser» la sorcellerie au XVII ${ }^{e}$ siècle. À partir de 1625 , il cesse de condamner les sorciers à mort après avoir qualifié le sabbat d'illusion. En Espagne, c'est aussi au début du xvII ${ }^{e}$ siècle qu'un débat embrase les défenseurs de la réalité du sabbat et les adversaires de cette idée, qui invoquent depuis le siècle précédent une explication médicale au sabbat, provoqué, disent-ils, par des substances narcotiques. Le sabbat ne serait qu'un rêve. Ce débat entraîne une réforme de la pratique inquisitoriale de la sorcellerie qui devra reposer dorénavant sur des preuves et non sur la simple présomption pour condamner les sorciers. C'est en comparaison avec l'époque moderne que la communication de S. Mulher, traitant de la psychothérapie américaine au $\mathrm{xx}^{e}$ siècle, prend tout son intérêt. Aux États-Unis, le sabbat est aujourd'hui en voie de criminalisation. Sous la pression fort médiatique de psychothérapeutes spécialisés dans les cas de malades à personnalités multiples qui déclarent des pratiques démoniaques, certains États (Idaho, Illinois, 1993) viennent de légiférer que la participation à un sabbat est un délit criminel. Les « psycho-démonologues » sont en effet persuadés que le sabbat est un événement réel ou une réalité virtuelle. Aussi se met en branle une véritable inquisition, qui se traduit par une vague de procès et un climat de panique à l'égard des satanistes qui ne manquent pas de nous rappeler celle que connut l'Europe à l'époque moderne. Le sabbat des sorciers reste donc un sujet d'actualité. 
Pierre Ragon, Les Amours indiennes ou l'Imaginaire du conquistador. Préf. Serge Gruzinski. Paris, Armand Colin, 1992. 15,5 × 24, 274 p., bibliogr., index.

La découverte du Nouveau Monde a suscité chez les Espagnols du xvi siècle une prolifération d'écrits dont les historiens n'ont pas encore exploité toute la richesse. Pierre Ragon nous offre un exemple de relecture de ces textes par ailleurs connus. À partir de chroniques portant sur la zone caraibe et méso-américaine, il a suivi l'évolution du regard que les conquérants ont porté sur la sexualité indigène. Qu'on ne se méprenne pas. L'auteur nous rappelle, avec bon sens, que ces textes nous en apprennent davantage sur les fantasmes et les tabous sexuels des Espagnols que sur le comportement des Indiens. Il s'agit donc de comprendre les raisons pour lesquelles la perception des Espagnols fut déformée à ce point.

Car, dans un premier temps, les Amérindiens furent accusés d'être des homosexuels, ce qui peut paraitre étrange, dans la mesure où, mis à part quelques cas de transvestisme avéré dans la région du Darien et quelques statuettes à la facture ambiguë, rien ne prédisposait à croire que l'homosexualité masculine - la seule qui comptât vraiment à cette époque - ait été répandue dans les sociétés indiennes. Bien au contraire, mais tous les chroniqueurs laïcs, à la suite d'Oviedo, ne se gênèrent pas pour colporter ce lieu commun. Puisque les Mexicains étaient des idolâtres et des anthropophages, ils devaient être aussi des sodomites. D'ailleurs, comment expliquer l'effondrement brutal de leur brillante civilisation devant une poignée d'Européens audacieux, si ce n'est à la lumière de la disparition subite de Sodome et Gomorrhe, perdues par leurs turpitudes. Le mythe de l'Indien sodomite avait un autre avantage. Il légitimait le coup de main de Cortez et les conquêtes ultérieures. Il fallut attendre la seconde moitié du $\mathrm{xvl}^{e}$ siècle pour que les missionnaires rétablissent la vérité.

Si les conquérants virent une utilité à faire passer les Indiens pour des homosexuels, le mythe des Amazones répondit à un autre usage. Tous les découvreurs pétris d'Antiquité et de romans de chevalerie ont entendu parler de ces femmes farouches et castratrices, tous les guerriers sevrés de femmes ont rêvé de les affronter et de les posséder, mais aucun ne les a jamais rencontrées. Les Amazones ont cela de particulier que, vivant à la limite du monde habité, elles reculent avec la frontière et demeurent insaisissables. Elles furent localisées successivement dans les Caraibes, dans la région du Panuco au nord-est du Mexique, en pays tarasque, enfin en Basse-Californie et dans le Sinaloa. Dans l'imaginaire du conquistador, la quête de l'or et la quête de l'Amazone sont étroitement associées, et le mythe des Amazones s'évanouit naturellement avec la saisie des territoires et des richesses.

Le thème de l'Indien lubrique connut, par contre, moins de succès. Il s'est développé dès les premiers temps de la Conquête en se nourrissant d'observations concrètes - la polygamie des élites, la beauté des femmes et leur naturelle nudité - mais aussi de fantasmes comme les cases sans portes qui firent croire à la promiscuité sexuelle. Mais très rapidement, le jugement se retourna : de lubriques, les Indiens devinrent des flegmatiques. C'est que les Européens appliquèrent ici la grille de lecture de leurs savoirs médicaux puisés à la tradition de Galien et d'Hippocrate. La théorie des humeurs se déploya dans toute sa logique. Tant qu'ils étaient lubriques, les Indiens passaient pour avoir un tempérament chaud et sanguin. Il fal- 
lait convenir qu'ils étaient des hommes, et de bons combattants, qui plus est. En devenant flegmatiques, ils glissaient du côté du froid et de l'humide, donc des femmes. Tous ces systèmes de classification avaient aussi leur utilité. Flegmatiques et donc paresseux, les Indiens justifiaient leur soumission aux yeux des colons.

La sexualité indigène ne fut donc qu'un prétexte saisi par les Européens du $x I^{e}$ siècle pour rendre plus lisibles les immensités amérindiennes qu'ils étaient en train d'assimiler. Ce voyage à travers l'imaginaire sexuel du conquistador espagnol révèle, en fait, les traits les plus profondément enfouis de la culture occidentale. Il est mené par l'auteur avec beaucoup de finesse et d'érudition. Le ton est toujours juste, la connaissance des sources parfaite et l'interprétation pertinente. Dans la masse des publications liées au cinquième centenaire, c'est un ouvrage à recommander, agréable à lire, ce qui ne gâte rien.

Jean-Michel SallmanN

Wolfgang KAISER, Marseille au temps des troubles, 1559-1596: morphologie sociale et luttes de factions. Trad. de l'allemand Florence ChaIX. Paris, École des hautes études en sciences sociales, 1992. $15 \times 23,412$ p. («Recherches d'histoire et de sciences sociales ", 52).

Au temps des troubles de religion, les luttes de factions aboutirent, à Marseille, une ville de 35000 habitants environ, à l'instauration d'une « dictature populaire »: sous l'autorité de Charles de Casaulx, la cité phocéenne devint, pendant cinq ans, de 1592 à 1596, une «république », quasiment autonome, au sein de la Ligue catholique. Cette réussite provisoire démontre la force conservée de la notion médiévale de la «bonne ville», fière de son indépendance et de ses libertés.

L'étude de Wolfgang Kaiser, qui s'inscrit dans le cadre des enquêtes menées par Robert Descimon, s'attache à comprendre et à expliquer cette aventure urbaine hors du commun. Une attention scrupuleuse est portée à la morphologie sociale, aux mécanismes de la vie politique, aux formes de la sensibilité religieuse : bastion du catholicisme, Marseille fut le siège d'un extraordinaire essor des compagnies de pénitents qui constituèrent, à côté des divisions territoriales de la cité, les noyaux de l'organisation ligueuse quand la ville se sépara du pouvoir royal en 1589 . La reconstitution du réseau très complexe des relations économiques, familiales et religieuses a permis de repérer les contours des factions (Marseille est dominée par des groupes familiaux entrecroisés) et leurs objectifs politiques. Ainsi, au-delà de son discours politique et religieux, la « dictature » de Charles de Casaulx s'est voulue l'expression d'une protestation sociale dirigée contre la monopolisation du consulat, des offices municipaux et des affermages des gabelles par la grande aristocratie marchande. En effet, une forte proportion de boutiquiers, de marchands, d'artisans et de paysans investirent le Conseil de ville pendant la domination de Charles de Casaulx: "Le bouleversement des relations de pouvoir apparaît comme une revanche de la terre sur la mer, du commerce local sur le grand négoce, de "l'autre" Marseille - Cavaillon, le terroir - sur le port» (p. 315-316); «La faction de 
Casaulx peut être considérée comme l'expression d'une "bourgeoisie seconde" (Henri Drouot) avec une coloration marseillaise spécifique, qui se dresse contre les tendances de l'aristocratie marchande à se couper de l'ensemble de la communauté de bourgeois » (p. 341).

Les sources de l'enquête sont nombreuses. On retiendra, notamment, le traitement des sources fiscales, le plus souvent lacunaires (l'« estime» de 1595, par exemple, un impôt général que décida de lever Charles de Casaulx) : il a permis de visualiser, avec une certaine précision, la répartition des biens, l'état des fortunes, les oppositions sociales, à partir d'un corpus de 2631 personnes (soit environ $10 \%$ de la population marseillaise). Une étude des mariages a aussi été menée à partir des Insinuations en la Sénéchaussée. Autorisant une analyse du «marché matrimonial » à Marseille, il met en valeur l'importance toute particulière de l'endogamie : 65,2\% des gentilhommes et écuyers mariaient leurs filles à l'un d'entre eux, $60 \%$ des marchands et des bourgeois agissaient de même, comme 69,6\% des revendeurs et des artisans. Et le lecteur appréciera l'attention portée aux itinéraires sociaux, reconstitués avec soin, comme celui de Maurice Sauron qui illustre bien la mobilité permise par les activités d'échange et de commerce. En 1547, ce dernier entrait chez Jean Jourdan, Léonard Corbière et $\mathrm{C}^{\mathrm{ic}}$, comme apprenti dans «l'art de la draperie ». Trois ans plus tard, il apparaît dans les archives comme « marchand». Huit ans après, il est désigné comme « noble écuyer », un terme qui signifiait qu'il avait abandonné le tiers et qu'il venait d'accéder juridiquement au rang le plus bas de la noblesse. En 1570, Maurice Sauron était deuxième consul de Marseille, et il finit sa carrière dans l'office de consul français à Alger après avoir été «capitaine entretenu par sa majesté en ses mers de Ponent et Levant [...] lieutenant de galère ».

On mesurera, avec ces quelques exemples, la richesse et l'intérêt de cette étude. Il est dommage qu'elle soit altérée par une écriture difficile, une dilution des idées centrales dans de longs développements et digressions qui font trop souvent perdre les fils de l'analyse.

Joël CORNETTE

Alain Crorx, L'Âge d'or de la Bretagne : 1532-1675. Rennes, Ouest-France, 1993. $14 \times 21,569$ p., bibliogr., index, cartes (« Histoire de la Bretagne »).

La parution de ce gros ouvrage d'Alain Croix est un événement important car il représente la synthèse la plus complète des travaux qui ont été menés depuis quelque vingt ans sur de nombreux aspects de l'histoire bretonne. Ces recherches, qui avaient besoin d'être confrontées et rassemblées dans une collection d'accès commode, permettent dorénavant d'envisager une « histoire totale » - politique, économique, démographique, sociale, religieuse, culturelle - à laquelle A. Croix s'est livré avec bonheur.

En évoquant dans son titre un «âge d'or " breton qui couvre une bonne moitié de l'époque moderne, l'auteur ne cherche pas à retrouver les indices disparus d'une certaine forme d'autonomie provinciale. En effet, la date de 1532, qui est celle de 
l'union officielle réalisée entre le duché et le royaume, est beaucoup plus qu'un symbole. Cette étape, préparée de longue-date, s'effectue en douceur et les notables bretons, qui continuent à s'exprimer dans le cadre des états provinciaux, se coulent sans amertume dans les institutions royales. Sans doute sont-ils particulièrement attentifs à la défense de leurs privilèges, mais il ne s'agit pas ici d'une spécificité bretonne, car à l'époque moderne, tous les corps du royaume, toutes les villes, toutes les provinces tiennent au maintien de leurs particularités. Inversement, le but du roi de France n'est pas véritablement la « centralisation » puisqu'il n'y enverra un intendant qu'en 1689. Il cherche davantage à trouver des relais efficaces dans le pays, par exemple en nommant des évêques dévoués. Cette intégration politique de la Bretagne dans le royaume s'effectue si bien qu'au cours de la première moitié du $\mathrm{XVII}^{\mathrm{e}}$ siècle, les révoltes restent assez rares, beaucoup plus rares que dans d'autres régions de l'ouest français - la Normandie ou la Guyenne par exemple. « Se soulever contre le roi? Mais où est-il en Bretagne, où les états servent d'écran, en matière fiscale notamment? Se soulever contre les collecteurs d'impôts? Mais en Bretagne, l'impôt direct est léger... » À cet égard, A. Croix note que les fameuses révoltes de 1675 , qui ont compté parmi les principaux soulèvements du règne personnel de Louis XIV, semblent avoir éclaté comme un véritable coup de tonnerre dans un ciel serein. Elle peuvent peut-être s'expliquer par les mutations de la pratique du pouvoir central au temps du Roi-Soleil, mais A. Croix préfere privilégier une autre piste : pour lui, ces révoltes expriment davantage une rupture dans l'équilibre socioéconomique de la province, la fin d'une longue période de prospérité dont son ouvrage tente de restituer les mécanismes.

En effet, la Bretagne du $\mathrm{XVI}^{\mathrm{e}}$ siècle et de la première moitié du XVII apparaît, selon ses propres termes, comme un « pays de Cocagne», du moins par rapport à d'autres régions, nettement plus défavorisées par la conjoncture. Par exemple, sur le plan démographique, il décrit la belle croissance de la population bretonne, dont la vigueur tranche nettement avec le reste du pays : au début des années 1660 , la Bretagne compte près de deux millions d'habitants, soit $10 \%$ du peuplement total du royaume. Certes, douze grandes crises affectent la population de vastes contrées entre 1532 et 1675 - avec une période extrêmement dure à la fin du xvi ${ }^{e}$ siècle : 1583-1584, 1591-1592, 1597-1598. Mais en même temps, elles ne sont pas assez sévères pour entraver en profondeur cet essor. Le climat, assez doux, y est peut-être pour quelque chose: «[...] une douzaine d'hivers rigoureux entre 1480 et 1540 , autant dans les soixante années suivantes, et quatorze dans les soixante premières années du Xvil ${ }^{e}$ siècle. » Mais pour A. Croix, la clef essentielle du dynamisme démographique breton réside plutôt dans la précocité de l'âge au mariage, car les jeunes filles bretonnes se marient en moyenne deux ans plus tôt que dans la plupart des autres régions. Leur période de fécondité est donc plus longue, et leur descendance plus nombreuse.

Sur bien d'autres points, la société bretonne tranche nettement avec le reste du royaume, et surtout avec les régions de grande céréaliculture. Par exemple, même si l'auteur note avec regret que la paysannerie bretonne reste encore trop mal connue faute de recherches systématiques, il en parle néanmoins avec suffisamment de finesse pour qu'il soit possible de bien saisir toute l'originalité du « modèle » rural breton. C'est ainsi qu'il insiste tout particulièrement sur l'importance de la polyactivité, avec des figures pittoresques de paysans «pluriactifs », comme ce Jean Braire, 
du village de Clis, qui possède au milieu du xvir siècle quelques bêtes et un peu de vigne, récolte et commercialise du sel, détient le matériel nécessaire au filage, et investit dans un pressoir avant d'ouvrir un cabaret... La polyactivité bretonne est certainement une réponse adaptée aux handicaps naturels de certains terroirs, mais elle semble aussi être l'une des clefs de la prospérité, puisqu'elle permet de répartir les risques inhérents à la production agricole en atténuant les effets des mauvaises récoltes.

Dans le domaine religieux, l'identité de la Bretagne est tout aussi frappante. Les procès de sorcellerie, par exemple, sont restés très rares. Pourtant, on en connaît la chronologie impitoyable et la diffusion massive dans d'autres régions de France, mais la Bretagne s'est largement tenue à l'écart de ce phénomène. De même, le protestantisme n'a pas réussi à s'implanter durablement et massivement. Les thèses de Luther, puis celles de Calvin n'ont même pas provoqué de grosses manifestations d'hostilité dans la population : elles se sont plutôt heurtées à une sourde indifférence, comme si elles étaient inadaptées à la culture bretonne, comme si elles étaient incapables de venir s'y greffer. Pour A. Croix, les explications de cette imperméabilité bretonne au protestantisme sont à la fois sociales et mentales, car non seulement la Réforme ne parvient pas à conquérir une partie notable du clergé, mais elle porte aussi en elle-même une tentative d'acculturation qui heurte de front une culture de la fête et de la mort profondément enracinée depuis des siècles dans les couches populaires.

A. Croix s'est attaché à construire une solide histoire culturelle de la société bretonne, dans laquelle il est à présent possible de glaner les informations les plus variées sur les sujets les plus divers : les superstitions des villes et des campagnes, les rites de la naissance, du mariage ou de la mort, les attitudes face au clergé, le logement, l'habillement, les lectures, les langages ou la nourriture. Il nous offre ainsi des pages fascinantes, d'une grande originalité, dans lesquelles il évoque par exemple, avec une certaine gourmandise, une «culture » ou une «civilisation » du beurre... Cet ouvrage foisonnant est donc destiné à servir de référence, car non seulement il fera date dans la production des ouvrages consacrés à la Bretagne, mais il deviendra aussi, sans aucun doute, un modèle qui ne manquera pas d'être imité par les auteurs qui tenteront à leur tour d'écrire l'histoire d'une province.

Laurent BouRQuIN

Peter Burke, Venise et Amsterdam. Étude des élites urbaines au Xvif siècle. Trad. de l'anglais par Odile Bernez. Brionne, Gérard Monfort, 1992. $17 \times 24,133$ p., ill., bibliogr., index ( Imago mundi »).

Comme son titre l'indique, cet ouvrage propose une étude comparée des élites urbaines de Venise et d'Amsterdam au XvII siècle, plus précisément de 1580 à 1720. S'appuyant sur des suggestions méthodologiques fournies par les sociologues, tout particulièrement par Vilfredo Pareto, P. Burke raisonne à partir de 563 individus - 244 Vénitiens et 319 Amstellodamois. Cette population recouvre les deux 
élites urbaines, ici définies suivant trois critères : un statut social élevé, un pouvoir important et une richesse considérable. Dans son souci de parvenir à « une histoire totale " de ces élites, l'auteur soumet ce groupe à huit questions qui constituent autant de chapitres dont on soulignera au passage la clarté et la concision.

L'étude de la structure de ces deux «patriciats » révèle une différence majeure entre une société d'ordres à Venise et une société de classes à Amsterdam. Dans la première ville, il existe un groupe étroitement (et juridiquement) défini, la noblesse, avec à l'intérieur un groupe plus lâche qui exerce la réalité du pouvoir; dans la seconde, il y a un groupe plus lâche et plus ouvert susceptible de gouverner, les citoyens, avec en son sein un groupe plus fermé qui exerce la réalité du pouvoir. L'ascension sociale, on l'aura compris, est plus difficile à Venise qu'à Amsterdam. L'organisation familiale diffère : à Venise, la forme dominante est la famille élargie, à Amsterdam, la famille nucléaire; les conséquences sont claires : dans le premier cas, les stratégies se fondent sur le groupe, dans le second, la réussite est avant tout individuelle. Les fonctions politiques exercées par ces deux élites confirment que Venise était une société plus structurée et Amsterdam une société plus ouverte.

Si les fondements économiques de ces deux élites reposent sur les mêmes piliers, la terre, les propriétés urbaines, les biens mobiliers, le commerce, on constate de notables différences quant à la distribution de la fortune et aux attitudes des hommes. La terre constitua à Venise une part importante de la richesse et, si certains eurent une politique active vis-à-vis de la propriété foncière, beaucoup se comportèrent en rentiers : il est ainsi frappant de constater que ces nobles, qui écrivirent tant, ne donnèrent aucun traité d'agronomie; quant à l'organisation des affaires, elle demeura toujours familiale : les Vénitiens n'investirent jamais dans des sociétés par actions. À Amsterdam, autour de 1700 , le schéma typique de la fortune était le suivant : la moitié dans les obligations, environ $32 \%$ en actions, $12 \%$ en maisons et $6 \%$ en terres. Près de la moitié de l'élite semble avoir été impliquée dans le commerce et un tiers eut des liens avec les Compagnies des Indes occidentales et orientales. L'attitude dominante à Venise serait celle du rentier, à Amsterdam celle de l'entrepreneur, avec, naturellement, des exceptions dans les deux cas.

Le mode de vie est nobiliaire à Venise où l'on prise hautement des valeurs de frugalité domestique, de sérieux, de dignité, de gravité, de prudence; au fil du temps, et surtout au xvIII ${ }^{e}$ siècle, un genre de vie plus luxueux et moins solennel se fait jour. Cet idéal personnel coexiste toujours avec le goût du faste officiel en l'honneur de la famille ou de l'État. À Amsterdam, l'élite n'a point de genre de vie traditionnel aussi conscient; toutefois, celui-ci acquit, au fil du temps, plus de grandeur comme en témoigne le vêtement: de la sobriété du noir, on passa à l'éclat des couleurs.

La formation de ces deux élites se ressent d'une organisation familiale différente. À Amsterdam, le jeune, éduqué dans un foyer restreint, est plus poussé vers l'extérieur, vers la réussite individuelle qu'à Venise où, élevé au sein d'un groupe familial large, il est moins porté à en sortir. Précepteur, collège et, éventuellement, université et voyage font dans les deux cas partie d'un même cursus qui se complétait par une formation pratique dans les magistratures. On notera que l'université hollandaise, en particulier l'Athenaeum d'Amsterdam, procédait de façon plus pragmatique, comme il ressort du célèbre discours que l'un de ses professeurs, Barlaeus, prononça sur le thème du mercator sapiens. 
Les intérêts intellectuels de ces deux élites divergent. À Venise, l'histoire domina, à Amsterdam, ce furent les sciences naturelles; et la tendance à l'innovation aurait été plus forte en Hollande. Quant aux attitudes religieuses, elles montreraient, dans la Venise catholique et dans Amsterdam majoritairement calviniste, une certaine convergence : dans les deux cas, coexistent, au sein de l'élite, un groupe de dévots et un groupe anticlérical.

Le mécénat est encore révélateur du comportement des deux patriciats. À Venise, palais, tombeaux, façades de l'église du quartier, protection des lettres et des arts témoignent éloquemment d'un mécénat familial et d'un goût artistique personnel. À Amsterdam, le mécénat demeura municipal et l'élite n'attacha pas aux palais ou aux tombeaux de famille la même importance symbolique qu'à Venise. Les goûts artistiques sont plus sobres à Amsterdam alors que l'ornement l'emporte à Venise.

Un dernier chapitre envisage l'évolution de ces deux élites au cours des années 1580-1720; il conclut sur le passage, dans les deux cas, d'une attitude d'entrepreneur à celle de rentier, autour de 1630 à Venise, vers 1700 à Amsterdam, c'est-à-dire plus tard que l'on ne le dit habituellement.

Cet ouvrage, tel que nous l'avons présenté dans ses grandes lignes, est précédé dans cette deuxième édition, par une introduction, où $P$. Burke précise son approche. Il s'interroge notamment sur le peu d'écho que l'histoire comparative a remporté, même s'il entrevoit un changement encourageant. Par ailleurs, il avoue : « J'écrirais ce livre un peu différemment si je le commençais aujourd'hui [...] la différence consisterait dans l'approfondissement de certaines approches que je n'ai fait qu'esquisser en 1974, plutôt que dans l'introduction de nouveaux développements. » Selon nous, cette « confession » explique, en partie, l'attention limitée que l'histoire comparative a recueilli, en particulier quand elle confine à l'inventaire de problèmes aussi nombreux que rapidement traités; de surcroît, une telle succession rapide de questions, aspects et sous-aspects, illustrés alternativement par l'un et l'autre cas, rend la lecture quelque peu lassante. Peut-être une telle histoire, dont l'ouvrage même de P. Burke souligne la valeur, serait-elle plus alléchante si elle privilégiait un petit nombre de questions, voire s'attachait à une seule. Mais on ne fera pas « la fine bouche » devant un ouvrage qui a le rare mérite, au-delà des informations nombreuses qu'il apporte, de donner à réfléchir sur le métier d'historien.

Françoise WAQUET

Giovanni CiPRIANI, Gli obelischi egizi. Politica e cultura nella Roma barocca. Florence, Leo S. Olschki, 1993. $17 \times 24,206$ p., bibliogr., index, 44 fig. (« Accademia toscana di scienze e lettere " "La Colombaria" », « Studi », CXXXI).

De Sixte Quint à Alexandre VII, les papes ont fait ériger des obélisques à Rome. Depuis lors, Rome ne se comprend pas sans ces signaux qui orientent le regard du touriste. Indicateurs ou phares pour les pèlerins des jubilés, ils représentent aussi une tentative de synthèse de l'ensemble de la sagesse universelle par Rome et la papauté. Derrière le goût pour ces monuments et l'égyptomanie qu'ils manifestent 
entre 1580 et 1680 , il faut lire la faveur dont jouissait l'hermétisme. Comme son maître Pie V, Sixte Quint n'aimait pas particulièrement l'Antiquité, mais il a fait une exception pour l'Égypte antique, en choisissant d'articuler son célèbre et gigantesque projet d'urbanisme par des carrefours et des places soulignés par des obélisques se renvoyant de l'une à l'autre. Ce projet étonnant commença à être exécuté dès 1586 , à grand renfort de publicité, par son architecte favori, Dominique Fontana.

Ce faisant, Sixte Quint se montre ouvert à l'humanisme de la Renaissance, car c'est Marsile Ficin et toute son école néoplatonicienne qui ont remis à l'honneur l'idée que les obélisques contenaient la philosophie des Égyptiens et qu'Hermès Trismégiste avait été le premier sage et le premier législateur de l'humanité, à l'âge de Moïse. Cette conception était fortement représentée dans la haute société romaine de la fin du $x v^{e}$ siècle et un homme aux antipodes de Pie V ou de Sixte Quint du point de vue de la conception du pouvoir ou de l'Église comme Gabriel Paleotti, cardinal-archevêque de Bologne et canoniste, la partageait totalement. L'élite romaine était donc persuadée que la récupération des obélisques de Rome aurait à la fois une signification spirituelle et un intérêt scientifique. C'était une façon de faire de Rome la synthèse de toute la sagesse antique, si chère aux savants du temps, avec la volonté affichée d'en faire aussi le parangon de la sagesse universelle. C'est pourquoi D. Fontana surmonta l'obélisque du Vatican des armes du pape et de la croix du Christ.

Le mouvement n'allait pas s'arrêter là. Tandis que les protestants, avec Isaac Casaubon, mettaient en doute, dès 1614 , l'authenticité de cette sagesse prétendument antérieure au christianisme, Campanella puis les jésuites, toujours avides de synthèse intellectuelle, en développaient au contraire l'étude, afin de confondre les hérétiques sur leur terrain, celui de l'exaltation de l'Église primitive. Casaubon venait trop tôt et déconsidérait trop vite un siècle d'hermétisme triomphant. Le médecin anglais Robert Fludd, ancêtre de la philosophie des rose-croix, ou le jésuite français Nicolas Caussin, plaçaient au contraire l'hermétisme au cœur d'une pensée adaptée au monde moderne autant qu'à l'apologétique pontificale.

Le plus important propagandiste en fut à Rome le jésuite allemand Athanase Kircher, un érudit fasciné par les secrets de l'univers, dont le travail sortit des presses de la Propagande de la foi en 1636. Il partait du principe que la langue copte conservait quelque chose de l'ancien égyptien et que, par conséquent, le christianisme s'enracinait en Égypte. Il réaffirmait que les inscriptions des obélisques contenaient toute la sagesse égyptienne. C'est sur ses indications que Le Bernin construisit le socle universaliste de l'obélisque des Quatre fleuves de la place Navone, en l'honneur d'Innocent X. Il posa ensuite l'obélisque de la Minerve sur un éléphant, allégorie de la sagesse antique dans Le Songe de Poliphile, manifestation de la sagesse absolue d'Alexandre VII maintenant.

Pour Kircher, dont le succès alla grandissant au cours du xvil ${ }^{e}$ siècle, Hermès Trismégiste était le descendant de Cham, le premier théologien et le premier législateur, le dépositaire de la tradition antédiluvienne et l'Égypte était le berceau de la sacralité et de la monarchie primordiales. Placer Rome sous le signe de cette sagesse, récapitulée par le Christ, c'était unir la Grèce, l'Inde, la Chine, le Japon, le Mexique, le Pérou. Il faut attendre la mort de Kircher, en 1680, pour que l'hermé- 
tisme disparaisse peu à peu de la propagande romaine ordinaire comme fondement de la sagesse universelle de Rome.

Les spéculations savantes de l'hermétisme, réservées aux élites certes, mais aussi outil pour penser l'unité du cosmos, doivent donc être associées à une entreprise universaliste, qui vise à faire de Rome l'héritière de la sagesse antique en même temps que la dispensatrice de toute sagesse. Ce sujet original et passionnant est abordé avec clarté. Le lecteur étranger regrettera seulement l'absence de construction du texte, qui l'oblige à glaner sa provende ici et là. Faute de conclusion, il est contraint d'en faire lui-même la synthèse et de s'adapter à cette culture des débuts de l'âge moderne, étrange et sophistiquée, dont il faut une fois de plus remarquer le succès dans la haute société intellectuelle, sans pouvoir en saisir l'extension ni l'influence véritable, faute de travaux sérieux et nombreux de sociologie des modes culturelles au $\mathrm{xvI}^{\mathrm{e}}$ siècle.

Nicole LeMAÎTRE

Marina RogGero, Insegnar lettere. Ricerche di storia dell'istruzione in età moderna. Alessandria, Edizioni dell'Orso, 1992. $15 \times 21,212$ p., index («Forme e percorsi della storia », 1).

Cet ouvrage regroupe sept études parues dans des revues ou des ouvrages collectifs, deux d'entre elles ayant même été publiées à deux reprises. C'est dire que ce recueil n'apprendra guère aux spécialistes qui suivent de près les travaux de M. Roggero; il n'en sera pas moins fort utile à ceux qui, peu familiers des réalités italiennes, trouveront là autant de bonnes monographies, toutes richement documentées, sur des questions majeures de l'histoire de l'éducation outre-monts.

Le volume s'ouvre sur une introduction d'ordre historiographique où l'auteur, parcourant la bibliographie récente sur le sujet (des universités à l'alphabétisation), met en avant les acquis de la production italienne et les lacunes qu'il reste à combler.

Les deux articles initiaux portent sur le collège jésuite. Le premier — « L'éducation de la classe dirigeante » - rappelle par son titre l'ouvrage de G. P. Brizzi qui, sous l'influence des travaux du père de Dainville, a relancé en Italie les études sur ce type d'institution. Toutefois, le propos de Marina Roggero est ici bien plus ample; se fondant sur l'abondante bibliographie que les collèges jésuites ont suscitée, elle offre une synthèse qui envisage de façon quelque peu encyclopédique tous les aspects liés à la naissance et à l'évolution de cette institution : lieux et dates d'implantation, objectifs et programmes, maîtres et élèves, rien n'est oublié, sans parler des rapports avec les autorités civiles et religieuses locales. Une telle approche, d'ordre macroscopique, a le mérite de fournir une excellente introduction au sujet, envisagé sous ses diverses facettes. A contrario, elle manque parfois de nuances : ainsi, la fidélité aux systèmes philosophiques et physiques traditionnels fut peut-être moins absolue que les recommandations officielles ne le laisseraient penser. Ainsi, dans les années 1680, le jésuite Ferroni qui enseignait à Bologne 
donna un Dialogo fisico contro il sistema copernicano, où l'on a vu un expédient pour exposer aux élèves le système condamné; de surcroît, on n'apprenait point dans ce collège la cosmologie de Ptolémée, mais un système qui empruntait beaucoup à Tycho Brahé.

Le second article s'inscrit dans la suite logique du premier, en envisageant à partir de l'exemple du Piémont la crise de ce modèle culturel que fut le collège jésuite. Dans un État qui ne brillait point par sa vitalité intellectuelle, les maîtres jésuites, au recrutement majoritairement local, ne furent pas des auteurs prolifiques ni novateurs, que ce soit dans les domaines de la théologie ou de la pédagogie; par contre, ils multiplièrent les écrits de circonstance, célébrant tout particulièrement les fastes de la maison de Savoie. Cet appui manifeste apporté à la monarchie n'en fut pas moins vain quand, sous l'influence de tendances juridictionnelles et de nouvelles exigences culturelles, les collèges jésuites perdirent de leur importance face à l'Université, avant de faire les frais de la décision royale de 1729 qui ôtait aux réguliers - et, en premier lieu, aux jésuites - le contrôle de l'instruction. Ainsi, dans ce cas limite que représente le Piémont, les jésuites, à la différence de ce qui se passa ailleurs, avaient été à l'unisson d'une culture locale peu dynamique et leur production, pourtant fort respectueuse de la monarchie, fut incapable de les sauver.

Les deux articles suivants sont consacrés aux universités italiennes à l'époque moderne. Le premier décrit et analyse les causes du déclin tant du corps professoral que de la population étudiante. La réponse que les hommes des Lumières apportèrent à cette situation postulait une diminution des autonomies universitaires, d'origine médiévale, et un contrôle de l'État sur l'Université; les exemples de Turin et de Pavie sont ici emblématiques. Sans contester la validité d'ensemble de l'analyse de M. Roggero, on rappellera toutefois que les universités italiennes du Sei-Settecento, si elles ne furent point des temples de la science vive, ne comptèrent pas moins de professeurs de talent qui, par leurs écrits comme par leur enseignement, contribuèrent au progrès et à la diffusion des idées nouvelles. Les «illuministi " ne naquirent point par génération spontanée. Dans la «mouvance» des universités, se situaient les collèges universitaires qui font l'objet du quatrième article : M. Roggero en retrace l'histoire, depuis ces fondations pieuses destinées à aider les étudiants pauvres jusqu'à ces institutions réservées aux élites et visant, pour certaines, à assurer à l'État de futurs serviteurs. L'histoire, toutefois, de ces collèges est loin d'être aussi linéaire et ces établissements constituent, déjà en raison de la diversité de leur taille, autant de cas particuliers.

Ces institutions, trop liées à l'Église et au passé, n'intéressèrent guère les réformateurs qui, à l'époque des Lumières, multiplièrent les projets destinés à rénover le système scolaire. C'est là l'objet du cinquième article de ce recueil. La pénétration des idées nouvelles, le souci de contrôle et d'uniformisation de la part de l'État, puis l'expulsion des jésuites rendirent nécessaires partout en Italie une réorganisation du système scolaire. Les obstacles ne manquèrent pas, et les réformateurs se heurtèrent tant au poids des traditions séculaires qu'au manque de moyens. L'écart fut donc grand entre les projets et les réalités, et il l'est encore plus lorsque, quittant la formation des élites, on se tourne vers l'instruction du peuple.

Ce dernier thème et, plus généralement, l'enseignement primaire sont au cœur du sixième article qui considère la situation piémontaise à la fin de l'Ancien Régime et sous la Révolution. Celle-ci se caractérise par une extrême diversité, juxtaposant 
aux écoles des communautés plus ou moins réservées aux fils de notables, des formes mineures et précaires ouvertes à un public plus vaste. Alors que l'enseignement et, en particulier, l'apprentissage de la lecture se faisaient en latin, et que dans le même temps le dialecte demeurait la langue unique pour les classes populaires, on peut s'interroger sur la compréhension que ces mêmes groupes sociaux eurent des affiches, placards et feuilles volantes qui, sous la Révolution, circulèrent en italien et en français. La structure de l'enseignement primaire ne fut guère affectée par les événements révolutionnaires : les fonds manquaient, d'autres priorités s'imposaient, et rares furent les maitres ouvertement jacobins. Si changement il y eût, ce fut dans l'affirmation d'une instruction universelle, qui ne privilégiât plus la seule élite. Mais, dans le Piémont révolutionnaire, cette aspiration demeura à l'état d'utopie.

$\mathrm{Au}$ début $\mathrm{du} \mathrm{XIX}^{\mathrm{e}}$ siècle, sous la domination française, l'instruction primaire connut une phase d'accélération, comme le neuvième article le démontre. D'une part, l'idée s'enracina du rôle positif que l'instruction représentait pour la société en général; d'autre part, une école élémentaire prit corps et un noyau d'enseignants recrutés en fonction de leurs compétences se constitua. Cela n'alla pas sans résistances. L'introduction du français se heurta à la persistance du latin, et l'école publique aux maîtres et aux écoles privées; de surcroît, les problèmes financiers et le poids des mentalités se conjuguèrent pour limiter les efforts de l'État dans sa tentative de réorganiser le système scolaire sous le signe de la centralisation et de l'uniformisation. Il fallut attendre plusieurs décennies pour que ces idées s'incarnent dans la réalité des faits.

Françoise $\mathrm{W}_{\text {AQUET }}$

Linda Timmermans, L'Accès des femmes à la culture (1598-1715) : un débat d'idées de saint François de Sales à la marquise de Lambert. Paris, Champion, 1993, $16 \times 24,937$ p., bibliogr., index («Bibliothèque littéraire de la Renaissance », série $3, \mathrm{t}$. XXVI).

En choisissant de s'interroger sur l'accès des femmes au savoir, Linda Timmermans s'est placée résolument au cour d'une interrogation plus vaste sur la condition féminine, sur le statut et la place des femmes dans la société. Le sous-titre de l'ouvrage précise l'angle d'approche du problème : l'étude des divers courants de pensée qui, au XVII ${ }^{\mathrm{e}}$ siècle, ont porté sur la possibilité qu'il y avait pour des femmes de se frayer une place dans le monde des choses de l'esprit; toutefois, l'auteur affirme son intention de prendre également en compte les réalités historiques contemporaines et donc le rapport dialectique qui existe entre la norme et le vécu. D'emblée, nous voudrions souligner la qualité de l'information sur laquelle cette étude repose : l'auteur a tout lu, sources anciennes et production moderne, et les quelque cent pages de bibliographie qui closent l'ouvrage constituent une véritable mine qui, sans nul doute, sera largement exploitée. Par ailleurs, cette étude patiente de textes aussi nombreux que variés est non seulement sans cesse éclairée par les acquis les meilleurs de l'historiographie, mais encore sous-tendue par une solide 
connaissance de la littérature française; ici, la prise en compte de la spécificité des genres évite bien des contre-sens et des anachronismes : sur ce point, on lira avec profit les pages excellentes consacrées aux panégyriques écrits par les «champions des femmes ".

L'ouvrage est organisé en deux grandes parties, bien équilibrées. La première porte sur la culture profane, mieux connue. L'auteur avoue très honnêtement sa dette envers ses nombreux prédécesseurs : ainsi, ses pages sur l'instance féminine dans la langue française doivent beaucoup aux travaux de Marc Fumaroli. Son mérite n'en est pas moins grand : d'une part, elle offre des synthèses fort heureuses sur nombre de points qui ont fait couler des torrents d'encre, tels la préciosité et le monde des salons; d'autre part, elle remet ensemble les pièces d'un puzzle que des études monographiques ne donnaient à voir que par morceaux détachés : elle est ainsi amenée à redresser bien des perspectives et à prendre en compte les interactions qui existèrent entre les diverses composantes d'un même ensemble. Dans un premier temps, elle s'applique à mesurer la place des femmes dans la vie intellectuelle et littéraire du temps. L' " amateurisme » reste la règle pendant tout le siècle : ce qui évolue, ce sont les centres d'intérêt (successivement l'humanisme, la préciosité, l'engouement pour les sciences) et le nombre des femmes qui se tournent vers les choses de l'esprit (même si l'on ne dépasse pas le cadre limité d'une élite de la naissance ou de la fortune). L'influence des femmes sur la littérature est liée à l'adoption par la civilisation classique de valeurs féminines, au premier rang desquelles la douceur et le naturel; elle ressort également du rôle qui leur fut reconnu dans la consécration des écrivains ou dans l'orientation du goût. Enfin, la seconde moitié du XvII ${ }^{e}$ siècle voit une «floraison de femmes écrivains » qui cultivèrent principalement les genres peu prisés des doctes et liés à la vie mondaine. Cela n'alla pas sans querelles ni polémiques qui firent trésor des arguments traditionnels d'inspiration féministe ou antiféministe, tout en prenant, avec le temps, une coloration originale : ainsi, dans la seconde moitié du siècle, il se développa une hostilité grandissante envers la femme savante, couplée avec un féminisme d'orientation mondaine. L'accès des femmes au savoir passe par le respect des bienséances, c'est-à-dire d'abord par la reconnaissance de la complémentarité des sexes.

La seconde partie prend en compte le rôle que des femmes ont joué dans la Contre-Réforme catholique, dans le courant mystique ainsi que dans les querelles jansénistes. L'auteur souligne l'intérêt que les réformateurs catholiques portèrent aux femmes, intérêt qui se traduisit notamment par la production de livres à leur intention; elle est ainsi amenée à analyser l'instruction chrétienne que l'on réservait aux femmes, les principes qui la réglaient et les moyens qui permettaient son acquisition (ici, de belles pages sur la direction de conscience). Les chapitres sur le jansénisme et la mystique où revivent les grandes figures féminines de la spiritualité française sont emblématiques d'une " promotion féminine par la religion ». La religion apparaît bien, en effet, comme un moyen important d'accéder à la culture et à la vie intellectuelle; mais, dans le même temps, des limites apparurent qui, nées du conformisme ambiant, du combat contre l'hérésie, de la montée de l'antimysticisme et du rationalisme, réduisirent le rôle que des femmes avaient pu un temps jouer dans l'Église, en se livrant à la direction de conscience, en distribuant un enseignement doctrinal ou en intervenant dans des querelles religieuses. 
Au terme de quelque huit cents pages, l'auteur peut conclure sur la tonalité défavorable du discours officiel concernant l'accès des femmes à la culture. Dans un monde fixe, où les rôles ont été définis une fois pour toutes, le savoir que les femmes acquéraient était nécessairement subversif, amenant une modification, voire un renversement des rôles. C'est à l'intérieur des limites imposées par la société que des femmes pouvaient avoir un rôle, voire une influence dans l'ordre des choses de l'esprit.

Sans nullement mettre en cause les acquis de cet ouvrage - et il aurait fallu des dizaines de pages pour énoncer les résultats d'analyses minutieuses d'un très grand nombre de textes - on est amené à formuler un certain nombre de remarques. Dans son introduction à ce qui est présenté comme « la version révisée et légèrement allégée d'une thèse de doctorat nouveau régime ", l'auteur fait part de son intention " de mettre à la disposition du lecteur un large corpus de textes » (p. 11). Si on ne peut que féliciter l'auteur d'avoir étendu le domaine de son enquête au-delà d'un certain nombre de textes «classiques », on a parfois l'impression que cette ambition l'a emporté sur l'énoncé vigoureux d'une thèse - au sens propre du terme. Encore, une telle impression de compilation est, à certains moments, renforcée par l'invocation aux « autorités contemporaines » qui, parfois, se succèdent dans le texte même à une cadence serrée; ainsi en une page (97-98) peut-on lire « remarque Marc Fumaroli», «Philippe Hourcade affirme», «affirme Christa Schlumbohm », «pour reprendre les termes de Ph. Hourcade», «Bernard Magné observe », « comme l'a montré Roger Duchêne ».

En second lieu, on est parfois surpris de trouver à côté d'analyses minutieuses soutenues par une annotation importante, des affirmations gratuites ou presque qui, par leur contenu même, arrêtent forcément l'attention. Un exemple suffira. On lit p. 223 : « $\grave{A}$ la fin du XviI ${ }^{e}$ siècle, beaucoup de femmes vivent de leur plume souvent très mal, il est vrai »; une note renvoie à $\mathrm{M}$. E. Storer, Contes de fées, pas$\operatorname{sim}$. On s'étonne qu'une constatation aussi importante (les seuls hommes de lettres, et encore une minorité d'entre eux, attendront un siècle le même résultat!) ne soit appuyée que sur une seule référence, qui plus est imprécise (passim). Sur cet aspect fondamental des choses, une démonstration solide s'imposait, qui eût amené, à partir d'une base quantitative nourrie, à s'interroger sur le nombre de femmes auteurs au $\mathrm{XVII}^{\mathrm{e}}$ siècle, leur statut social et leur condition économique.

On s'interroge encore sur la pertinence d'un plan qui, dans la perspective de l'accès au savoir ou à la culture (ici, il y a des flottements), sépare le profane et le religieux. D'ailleurs, dans les deux cas, une conception générale du monde avec ses rôles bien distribués et ses bienséances ne rend-elle pas également compte des choses? Ce qui naturellement ne veut pas dire que les femmes n'aient pas réussi différemment dans les deux domaines. Peut-être convenait-il de partir de cette conception de la femme que Huarte et ses confrères avaient popularisée et qui rendaient $a$ priori la femme inapte au savoir.

Enfin, si dans l'ensemble, cet ouvrage échappe avec bonheur aux travers habituels des women's studies, l'emploi des expressions «féminisme apologétique », « intellectuel » ou « religieux » n'est pas sans poser problème dans l'ordre de l'analyse historique. Et quand l'auteur écrit p. 281 : «Dans la première moitié du siècle, l'accès au savoir devient une revendication essentielle du mouvement féministe... », l'on s'interroge sur la consistance et la cohérence d'un tel mouvement. 
Ces observations n'enlèvent rien aux qualités de l'ouvrage de L. Timmermans. Elles témoignent avant tout de l'intérêt que l'on a pris à la lecture d'un livre dont on soulignera encore la richesse de l'information. À ce titre mais aussi par son ampleur, il est appelé à servir de référence dans les études consacrées à la femme au XVII ${ }^{e}$ siècle.

Françoise WAQUET

"Culture et société dans l'Europe moderne et contemporaine", sous la dir. de Dominique Julia, Annuaire du département d'histoire et civilisation, 1992. Florence, European University Institute, 1993. $15 \times 23,230$ p., bibliogr.

Annuaire du département d'histoire et civilisation de l'Institut universitaire européen de Florence, ce premier volume se veut le reflet des activités et des problématiques des chercheurs du centre. Lieu de confrontation entre historiens de diverses nationalités, de rencontre entre des traditions et des méthodes d'investigation plurielles, cet espace a désormais enregistré suffisamment de matériaux pour lancer une nouvelle revue. Dominique Julia a coordonné et rassemblé les cinq contributions ici présentées, toutes ressortissant de cette discipline en plein essor qu'est l'histoire culturelle. Deux études, l'une sur le contrôle des livres par l'Inquisition, l'autre sur l'édition populaire parlent directement de la circulation des écrits. Une troisième les retrouve indirectement, par le biais des lectures et de la culture des militants communistes italiens de la période 1946-1956. Une autre contribution aborde l'Angleterre du xvil ${ }^{e}$ siècle au moment où un cabaret littéraire sert de masque à un des premiers clubs politiques du pays. Enfin, les lieux de mémoire français et allemands font l'objet du dernier article de fond. Ainsi les aires ibérique, italienne, britannique, germanique et française sont-elles prises en compte dans un volume qui a toutes les allures d'un work in progress puisque la plupart des auteurs sont en cours de rédaction de leur thèse. L'exposé d'un aspect de leur recherche ou d'un axe de leur problématique se veut alors appel à remarques, discussions, critiques, ce qui correspond aux finalités et aux ambitions intellectuelles de l'Institut universitaire européen de Florence.

Travaillant sur «Les Inquisitions modernes ", Francisco Bethancourt propose une réflexion sur «les visites inquisitoriales de contrôle des livres» dans la péninsule Ibérique à partir de 1551. Loin de s'en tenir à une description des mécanismes utilisés par la police de l'Église - visites domiciliaires dans les imprimeries, librairies, bibliothèques, navires entrant au port, auberges logeant des étrangers, etc. - il souligne le poids de la censure lorsque les mesures de coercition deviennent obsolètes et tombent en désuétude. Le paradoxe apparent consiste à observer le relâchement de la censure matérielle à une époque - le Xvir ou le Xviri siècle - et l'absolue rigueur du contrôle social qui transparaît lorsque l'on dresse le catalogue des bibliothèques du temps. Pourquoi ne trouve-t-on pas les livres que le pouvoir ne pourchassait plus avec autant de rigueur qu'auparavant? La réponse du chercheur est importante parce qu'elle dépasse le cadre spatio-temporel de son travail. Pour lui, aucune 
censure policière n'interdit la circulation des idées mais celles-ci se réfugient dans des cercles limités, ce qui leur ôte toute influence profonde sur le mouvement général de la période. Cette conclusion n'est pas généralisable partout ni toujours mais elle invite à méditer la force presque atemporelle des mesures de contrôle social. Quand elles ont perdu leur efficacité, le poids des habitudes, l'inertie les maintiennent en vigueur très longtemps.

Gabriella Solari a choisi les imprimés populaires dans l'Italie du XIX ${ }^{e}$ siècle et elle a privilégié les livres à un sou, deux sous ou trois sous pour pénétrer à l'intérieur de la culture du peuple. Son corpus recense des textes disparates, livrets de dévotion, feuilletons comparables au «roman à 4 sous » français, etc. Proche de Roger Chartier dans sa définition de l'imprimé populaire, celui que l'éditeur destine matériellement à cette catégorie sociale, Gabriella Solari essaie de prolonger cette réflexion en fixant l'apparition d'un marché du livre populaire. Cela suppose des éditeurs spécialisés, des clients potentiels et des produits fabriqués à leur intention. Dans un pays comparable à l'Espagne pour le retard dans l'alphabétisation des masses, un décalage avec la France est évident. C'est donc après 1870 que les Salani, Sonzogno et autres professionnels vont produire par dizaines de milliers les brochures, feuilles volantes, feuilletons illustrés que colporteurs et crieurs de rues, tenanciers de kiosques à journaux mettront en circulation, au détriment de la librairie traditionnelle. Comme dans le cas de la bibliothèque bleue française, on observe la récupération d'auteurs anciens, de formes littéraires abandonnées par les élites, ce qui amène à relire la culture du peuple comme un mixte, un hybride préparé par des greffes multiples avant que des militants politisés ne décident de construire une nouvelle culture pour le peuple.

Mauro Boarelli, en étudiant la culture et le parcours de formation des militants du PCI, fait en quelque sorte écho aux propositions de Gabriella Solari puisqu'il situe cette culture de base entre l'oralité et l'écriture, à la charnière où l'imprimé populaire, lu à haute voix, chanté, crié, ânonné, pénétrait partout, même chez les nonlecteurs. Travaillant sur des « biographies » - appellation officielle dans les partis communistes, bien préférable à celle d'autobiographie, trop connotée socialement comme activité petite-bourgeoise - de cadres moyens, conservées à l'institut Gramsci de Bologne, et rédigées entre 1946 et 1956, le chercheur a essayé de dégager leur background culturel afin de mieux comprendre comment ces hommes avaient ensuite interprété leur histoire. Alphabétisés dans leur jeunesse pour la plupart, ils sont venus à la politique par l'usage de la parole et de la radio plus que par la lecture du journal. Toutefois, la découverte des inégalités sociales a souvent été médiatisée par une lecture collective de textes littéraires. Ceux-ci se retrouvent alors dans la bibliothèque du militant : Jack London, Gorki, etc. En amenant les auditeurs de ses écoles à écrire sur eux-mêmes, à s'arracher à leur environnement immédiat, à s'émanciper du contrôle de la communauté, le PCI aurait réussi ce que l'Église catholique n'avait jamais osé, offrir à ces hommes une dignité neuve qui passe par la connaissance de soi comme sujet. Observable en Émilie-Romagne où l'industrialisation fut tardive, ce modèle nous semble cependant aléatoire parce qu'à la différence des autobiographies analysées par Philippe Lejeune en France, il s'agit ici de « biographies » commandées par un parti, ce qui rend délicate l'assimilation proposée. 
Pascal Brioist a repris, lui, le dossier de la taverne la plus célèbre du vieux Londres, la « Mermaid Tavern », où passèrent selon la tradition littéraire Shakespeare, John Donne et Ben Johnson. Détruisant les mythes qui encombrent la chronique de la Sirène, l'historien découvre un club politique lové dans une réunion d'écrivains et dramaturges de renom. Lieu d'intégration sociale, de communication et de sociabilité, la taverne proche de la Tamise offrait les garanties de sécurité dont les clients pouvaient avoir besoin. Beaux esprits, lettrés, juristes de formation, bourgeois aisés plus que nobles, proches du pouvoir, exerçant des fonctions au Parlement, les membres du club se voulurent une aristocratie de l'intelligence, ce qui implique des rapports égalitaires et non de patronage. Toutefois, les modèles aristocratiques se diffusaient aussi dans cet espace et les hôtes de la Sirène n'étaient pas unanimes dans leurs options religieuses ou politiques. Au terme d'une analyse rigoureuse, subtile, l'auteur aboutit à une mise en cause de l'opinion de Jürgen Habermas selon laquelle la sphère publique littéraire aurait précédé la sphère publique politique. Les deux domaines se sont probablement interpénétrés sans que les contemporains aient nettement conscience de ce qui relevait de l'un plutôt que de l'autre.

Avec Charlotte Tacke enfin, ce sont les lieux de mémoire français et allemands qui font l'objet d'une enquête comparative. Reprenant le dossier déjà fourni des héros des deux nations, Vercingétorix et Hermann (Arminius), tous les deux guerriers magnifiques de la résistance à l'invasion romaine, elle entend démontrer l'identité de la construction du mythe nationaliste. Au-delà du Rhin, l'érection d'un monument en 1841 coïncide avec une crise anti-française. De ce côté du fleuve, la défaite de Sedan réactive le culte du chef gaulois et le nationalise. Gallomanie et teutomanie, gallophobie et germanophobie se sont donc mutuellement conditionnées. Toutefois, là où, en France, la défaite de Vercingétorix est vécue comme le vecteur de la pénétration de la civilisation, par le biais de l'acculturation romaine, le fait d'armes de Hermann est censé, lui, avoir préservé la culture germanique, la pureté du deutsche Volk. De ce fait, le mythe de Hermann situe la nation allemande dans son éternité, soudant le peuple autour de son roi, rejetant tous les éléments extérieurs à la nation. La Kulturnation allemande et, au contraire, la nation politique française procèdent de deux constructions mythiques, historiquement datées et contemporaines de l'émergence des deux nationalismes. Autre différence essentielle, les Allemands ont rendu hommage à leur héros dans la forêt de Teutoburg pour symboliser l'union avec la nature, la terre-mère, alors que les Français ont privilégié les villes, Gergovie notamment.

Nul doute qu'une telle revue, aussi riche de contenus divers, aussi destinée à une lecture critique, ne soit appelée à un bel avenir. Souhaitons que sa diffusion abandonne la confidentialité qui fut la sienne pour ce premier volume et qu'elle conserve cette fraîcheur, cette spontanéité qui font le mérite de cet Annuaire voué à la présentation des thèses en cours d'achèvement. 
Jean-Louis HaRouel, L'Embellissement des villes: l'urbanisme français au xvII' siècle. Paris, Picard, 1993. $17 \times 24,336$ p., bibliogr., index («Villes et sociétés »).

Les transformations du paysage urbain au xvIII ${ }^{e}$ siècle manifestent l'affirmation de préoccupations pratiques et la récurrence du souci de régularité. Cette double dimension fonde l'originalité de l'urbanisme du Siècle des lumières, qui se montre soucieux d'embellissement. Partant de ce constat, Jean-Louis Harouel, historien du droit, s'intéresse aux mécanismes juridiques et administratifs qui règlent l'urbanisme de cette époque. Son approche, beaucoup plus pointue que ne le laisse deviner le titre de l'ouvrage, est novatrice. En effet, elle ne laisse subsister aucune zone d'ombre sur le cadre juridique au sein duquel l'urbanisme du xvIII ${ }^{e}$ siècle s'épanouit.

En matière de voirie, les héritages sont lourds, et l'enchevêtrement des autorités compétentes bloque souvent les initiatives. Au xvirI ${ }^{e}$ siècle, la volonté d'aménagement de la ville l'emporte sur le simple exercice de la voirie. Parallèlement, les autorités traditionnelles (Bureaux des finances, seigneurs) sont disqualifiées au profit de la toute-puissance centralisatrice des intendants. J.-L. Harouel analyse l'appareil réglementaire concernant la mitoyenneté, le permis de construire et l'alignement, ou encore les règles de police sur la prévention des incendies, la salubrité et la solidité des bâtiments : il dénonce une volonté de régulariser la ville. L'ouvrage, à travers une présentation minutieuse d'exemples régionaux, nous plonge au cour des procédures qui visent au redressement d'une rue ou à l'adoption d'un programme architectural sur une place (la densité des illustrations renforce de façon agréable le propos de l'auteur, ce qui n'est pas le cas des trop nombreuses coquilles qui émaillent le texte). Ainsi, la diffusion de plans d'élévation, accompagnant les demandes de permis de construire, accentue le contrôle des pouvoirs sur les formes architecturales. Ce type d'évolution permet d'éclaircir, selon nous, les relations entre l'action du pouvoir, la pratique des hommes de l'art et l'esthétique d'une époque.

Prenant le contre-pied des thèses de Pierre Lavedan, J.-L. Harouel démontre que les villes sont des acteurs essentiels de l'urbanisme du xvil ${ }^{e}$ siècle. Le corps de ville est un bailleur de fonds sans lequel aucun projet ne peut aboutir, et sa résistance à certaines réalisations, comme c'est le cas à Lyon en 1766 face à l'opération de Perrache concernant le confluent Rhône-Saône, s'explique par un réalisme conscient de la démesure des aménagements prévus. Les états provinciaux, dont les ressources et l'autonomie sont importantes, jouent un rôle moteur dans l'affirmation d'un urbanisme qui prend en compte les besoins d'équipement des villes. Leur intervention dans les villes est un bon indicateur de leurs relations avec le pouvoir royal. Au dynamisme des états du Languedoc, qui initient en 1768 un aménagement des quais et des ports sur la Garonne toulousaine, on peut opposer la résistance des états de Bretagne qui ne financent que les places royales.

Le roi utilise la planification urbaine pour surmonter l'inertie des autorités traditionnelles et le plan d'alignement adopté par un arrêt du Conseil fait de l'intendant « le maître de la morphologie urbaine ", selon J.-L. Harouel. Il souligne que le trinôme intendant-corps des Ponts et Chaussée-Conseil du roi est déterminant dans la transformation des villes au xviI ${ }^{\mathrm{e}}$ siècle. Ainsi, «le projet planificateur du 
Siècle des lumières » prend corps dans la rencontre d'une réglementation de plus en plus fine avec la généralisation du plan d'alignement. La production de formes urbaines originales va de pair avec l'émergence d'un cadre juridique cohérent. La reconstruction de Rennes après l'incendie de 1720 est l'exemple le plus achevé de cette ambition, le feu ayant fait table rase de la structure urbaine existante.

En analysant le cas exceptionnel de Rennes, J.-L. Harouel note à juste titre les limites de cette planification urbaine. Elles sont de deux ordres : le pouvoir n'intervient tout d'abord que sur un mode normatif. On pourrait à cet égard s'interroger sur cet idéal de régularité que J.-L. Harouel attribue au xvir ${ }^{e}$ siècle. N'est-il pas l'expression privilégiée du contrôle centralisé de l'urbanisme plutôt qu'une nouvelle esthétique? Surtout, l'impossible financement de bien des opérations freine l'ardeur de cet urbanisme. L'abandon d'un mode de financement par le voisinage laisse les fonds publics seuls capables de faire face à la transformation de la ville. Le recours à l'impôt, la création de droits d'octroi, et surtout l'emprunt, qui laisse exsangues bien des villes, ne permettent qu'une réalisation progressive des plans d'alignement dont les résultats ne sont perceptibles qu'à long terme. Ainsi, le premier plan général d'alignement n'interviendra dans la capitale qu'en 1783, témoignant de la maturation d'un urbanisme qui englobe la ville dans sa totalité. La dernière limite de la planification, sur laquelle on pourrait insister davantage que ne le fait J.-L. Harouel, c'est la résistance des particuliers à certains projets, celle-ci dénonçant le décalage entre les conceptions des décideurs et les pratiques des citadins qui ne voient pas la régularisation d'une rue du même œil.

Seul l'urbanisme opérationnel réalise des pans entiers de projets de planification, en modifiant des quartiers anciens et en dotant les villes d'équipements comme les ponts, les fontaines et les jardins. L'ampleur des transformations prévues privilégie deux types de mise en ceuvre. L'utilisation de terres domaniales dispense de l'achat des terrains et limite la distribution d'indemnités liées à une expropriation. À cet égard, la procédure s'unifie à partir du milieu du xvIII ${ }^{e}$ siècle, prévoyant une détermination de gré à gré et le recours à une tierce personne entre la puissance publique et le particulier en cas de litige. J.-L. Harouel montre bien comment la Révolution française, à travers la Déclaration des droits de l'homme et le code civil, a systématisé des solutions mises en place par l'Ancien Régime, et qu'ainsi elle ne constitue pas un tournant pertinent dans ce domaine. La spéculation des particuliers est le second vecteur de la réalisation de projets d'urbanisme. Aristocrates, établissements religieux, financiers lotissent leur terrain et donnent naissance à des quartiers entiers, comme la Chaussée d'Antin à Paris en 1770. L'obligation de construire rapidement, qui accompagne l'autorisation accordée, et des aides à la construction, comme des exonérations fiscales, donnent un rôle prédominant à ces initiatives privées dans la transformation des villes à la fin de l'Ancien Régime. Leur programme architectural uniforme marque souvent une rupture avec le paysage urbain environnant. J.-L. Harouel reprend à son compte, pour qualifier ces réalisations, l'expression de « fragments de ville ». Il souligne leur effet disparate dans le tissu urbain et la difficulté pour le pouvoir d'harmoniser des opérations sur lesquelles il a peu de prise.

J.-L. Harouel montre bien que l'urbanisme du xvIII siècle est un des éléments fondateurs de l'unité française grâce à l'uniformisation progressive de la réglementation. Mais la centralisation et la simplification des procédures ne peuvent à 
elles seules expliquer cette nouvelle efficacité qui fait dire à $J_{\text {.-L. }}$. Harouel que le $X V I I I$ e siècle a « une passion pour l'aménagement urbain ». Le prisme juridique ne permet de saisir qu'une facette de l'urbanisme de cette époque et les conclusions de J.-L. Harouel demanderaient parfois à être pondérées par l'examen d'autres sources et l'application d'un questionnement qui prenne en compte tous les acteurs de la ville.

L'exemple de l'abandon de la politique de limitation de la capitale donne l'occasion à J.-L. Harouel de soulever cette difficulté. Il constate qu'au Xvirle siècle, la législation mise en place pour limiter la croissance de Paris n'est pas respectée. L'ampleur de l'enceinte des fermiers généraux entérine une croissance manifeste. Connaissant les problèmes de contrôle et de ravitaillement de la capitale à cette époque, il est préférable de pointer les contradictions que rencontrent le roi et le Bureau de la Ville face à cette croissance plutôt que de déplorer, comme l'auteur le fait, l'absence de prise en compte du phénomène. Cette enquête aurait amené J.-L. Harouel à s'interroger sur les mécanismes et les représentations qui conduisent l'évolution de l'espace urbain sous l'Ancien Régime. Affirmer que Paris fut privée d'une croissance urbaine planifiée « qui était dans la logique de l'Ancien Régime », c'est juger, avec un regard trop moderne, et faire le procès d'un siècle qui a mûri des solutions qui seront largement reprises au siècle suivant. En témoigne, le plan d'alignement général commandé à Edmé Verniquet en 1783, magnifique « outil de transparence urbaine ", qui sera utilisé au $\mathrm{xIx}^{\mathrm{e}}$ siècle.

J.-L. Harouel achève son étude en réfutant la qualification d'urbanisme « frôleur » au sujet du xviIt siècle. Il rappelle que l'urbanisme français de ce siècle, « qu'il le recherche consciemment ou l'obtienne incidemment », engendre un paysage urbain marqué par l'unité architecturale. L'alternative montre bien la complexité des enjeux qui président à la transformation des villes. Cette dernière oblige le chercheur à prendre en compte un large champ d'enquête que l'ouvrage de J.-L. Harouel ne manque pas d'éclairer d'un jour nouveau.

Isabelle BACKOUCHE

L'Anticomanie. La collection d'antiquités aux XVII' et XIX siècles. Textes rassemblés par Annie-France Laurens et Krzysztof Pomian. Paris, Éd. de l'École des hautes études en sciences sociales, 1992. $16 \times 24,352$ p. («Civilisations et sociétés », 86).

Ce livre, fruit d'un colloque organisé en 1988 par l'université Paul-Valéry à Montpellier sous l'autorité d'Annie-France Laurens, qui en introduit les différents chapitres, s'inscrit dans la mode relativement nouvelle de l'histoire "au second degré ». Sa justification est exposée d'entrée de jeu par Francis Haskell : «L'étude de l'Anticomanie est aussi importante que celle de l'Antiquité elle-même. » Dans l'inspiration de son grand livre Taste and the Antique (1981), traduit en 1988 sous le titre Pour l'amour de l'antique. La statuaire gréco-romaine et le goût européen, 1500-1900, ce recueil s'attache en effet à un type de collectionnisme et à un siècle, 
de 1750 à 1850 , pour brosser le tableau d'une mode considérée davantage du point de vue de ce qu'elle révèle, quant à la civilisation européenne, que comme simple épisode de l'histoire des collections.

L'ambition est d'analyser, de l'Ancien Régime jusqu'à la fondation de l'archéologie contemporaine et au système actuel des musées, l'amour, la collection, l'étude du passé antique, en envisageant les activités qui lui sont directement liées (commerce, voyage, restauration), ainsi que son administration concrète, comme fait matériel, au sein des musées: du British Museum au Louvre, du musée Calvet d'Avignon (M.-P. Foissy-Aufrère) aux musées disparus comme la collection Campana (E. et J. Gran Eymerich) ou celle de l'École des beaux-arts (Ch. Pinatel). Le propos des deux premières parties s'organise autour de quelques personnages, célèbres ou non, de collectionneurs ( $G$. Bruyère et $H$. Lavagne donnent une excellente monographie de François Artaud). La deuxième partie considère le passage au musée et à la science, enfin, la dernière envisage les aspects davantage esthétiques de cet intérêt (telles les études sur la collection de vases étrusques acquise par Ingres pour l'École des beaux-arts ou le musée de Montauban, ou la collection des statues de plâtre de l'académie San Fernando à Madrid).

Les différentes communications, trop nombreuses pour qu'on les évoque toutes ici, sont donc fort variées. L'attention va des sculptures grecques et romaines aux monnaies ou aux vases, et comprend aussi les antiquités nationales du $\mathrm{XIX}^{\mathrm{e}}$ siècle. Il s'agit pour certains d'enquêter sur l'accumulation et les pertes d'un patrimoine, pour d'autres de retracer le rôle des premiers archéologues. Certains sont encore attachés à un propos « axiologique », qui veut définir ce que « vaut » telle ou telle collection, tandis que d'autres proposent une histoire de la collection entendue comme espace d'élaboration et d'expression d'une culture. Une illustration paradoxale en est fournie par la communication de Paulette Ghiron-Bistagne sur une poupée articulée du musée Borély, qui démontre que l'étude des faux apporte des éléments précieux à l'analyse de l'horizon d'attente d'une époque en matière d'antiquités légitimes. Bref, les collections apparaissent à la fois comme des supports didactiques, des objets de jouissance esthétique, ou bien encore les témoins d'une pureté mythique, permettant l'affirmation d'une identité hic et nunc.

La communication de $\mathrm{K}$. Pomian est à cet égard exemplaire, qui brosse le panorama des « deux pôles de la curiosité antiquaire ». Il identifie le premier à une curiosité romano-gréco-égyptienne, bref classique, étendue au cours du premier xIx siècle au Proche et au Moyen-Orient. Commun à toutes les élites européennes, ce premier corpus d'œuvres et de monuments figure l'universel et définit le Beau idéal, surtout dans la grécomanie issue de Winckelmann. L'importance des collections de modèles pour les académies, liée au nouveau classicisme, en est une des illustrations, comme le montre A. Ubeda de Los Cobos. Le second pôle est en revanche davantage hétéroclite, à la fois plus récent (médiéval, voire moderne) et local (gaulois, germanique, celtique, slave...), mais encore lointain et "ethnique ». Au cours d'une évolution longue et complexe, il donnera lieu, au XIX ${ }^{e}$ siècle, au patrimoine défini comme ce qui permet aux nouveaux États-Nations de « justifier tantôt le programme de la lutte pour leur indépendance tantôt leurs revendications à l'égard d'États limitrophes " (p. 63). L'invention de traditions dans le nationalisme romantique s'accompagne de mythologies d'antiquaires : l'hypothèse celte convainc certains historiens français, allemands et britanniques, la mythologie des Goths 
triomphe auprès des Scandinaves et celle des Sarmates satisfait l'orgueil national polonais, en fonction des «leçons » d'étymologies de fortune, mais à prétention scientifique. Éléments obligés de la culture de la curiosité à l'époque moderne, ces antiquités se voient reconnaître une valeur d'art vers 1750 en Angleterre, 1830 en France et en Allemagne. Dernière étape, la découverte des grottes de Lascaux en 1940 suscite une reconnaissance esthétique des objets préhistoriques. Parallèlement à ce panorama inspiré par l'histoire des idées, d'autres communications mettent en avant le poids des représentations muséographiques.

Wolfgang Ernst esquisse ainsi une histoire de l'imaginaire social de la galerie et de l'innovation au musée public, contre l'idée d'un passage obligé du désordre des collections privées à l'organisation savante, historiciste, des œuvres au sein du musée, parallèlement au triomphe du catalogue savant. Le cas du British Museum lui permet de montrer le contraire : issu de l'achat par le Parlement d'une collection de curiosités et d'objets d'histoire naturelle, enrichi peu à peu d'autres collections, il témoigne d'une particulière incertitude entre collection privée et musée public, entre l'ancien et le moderne. Les collections demeurent hétéroclites, tandis que le propos du connoisseurship, lié à l'habitus du propriétaire, persiste, contre l'ordre abstrait de l'histoire de l'art. Dès lors l'histoire du cadre muséal est moins à chercher dans la réalité architecturale du lieu ou dans les exposés savants qui veulent en établir les principes que dans cet « archi-musée » que dessinent les vues « artistiques » des salles et les collections idéales chères aux représentations cultivées d'une époque.

Pareil ouvrage, qui porte moins sur les contenus successifs d'une mémoire de l'Antique tenue pour identique au cours des âges que sur l'idée de collection d'antiques elle-même et les mutations tant de son goût que de sa physionomie, manifeste combien le temps est le sujet même du travail historien. Dans cette perspective devrait s'élaborer une histoire des formes et des appropriations de la survie culturelle, dont ce colloque fort riche retrace quelques-uns des avatars.

Dominique Poulot

René-Marc Pille, Adelbert von Chamisso vu de France, 1805-1840. Genèse et réception d'une image. Paris, CNRS Éditions, 1993. 15,5 × 24, 128 p., bibliogr., index ( $«$ De l'Allemagne $»)$.

À travers l'exploration d'un fonds d'archives - la correspondance des deux frères de Chamisso - conservées à la Staatsbibliothek de Berlin, c'est le tableau de la réception de la culture française en Allemagne au début du $\mathrm{XIX}^{\mathrm{e}}$ siècle que nous propose R.-M. Pille. Plus qu'à son frère, Hippolyte, émigré comme lui en 1792, mais rentré en France sous le Directoire, c'est à Adelbert demeuré en Allemagne et devenu de ce fait écrivain allemand que s'intéresse l'auteur. C'est donc une vision inhabituelle des transferts culturels franco-allemands qu'il nous est ici donné de découvrir, un peu l'envers du décor à travers une personnalité que son éclectisme rend attachante. Avant de se consacrer à la botanique - il fut en charge du Jardin botanique de Berlin - Adelbert von Chamisso fut d'abord écrivain, composant des 
cycles de poèmes mais surtout auteur à succès du Peter Schlemihl. C'est à cet aspect de son cuvre que s'est arrêté R.-M. Pille.

R.-M. Pille est plus classique dans sa présentation de la réception française de l'œuvre d'Adelbert von Chamisso. On voit tour à tour entrer en jeu trois différents réseaux de transmission, dont chacun renferme quelques grands noms de la culture française de l'époque. Sur ce point, l'auteur a raison de souligner la qualité de ceux qui firent connaître en France l'œuvre de Chamisso. Les distorsions qu'elle subit en sont d'autant plus intéressantes. Le premier réseau chronologiquement est celui des juifs arrivés d'Allemagne au début du siècle. Le deuxième s'organise autour de la personnalité d'Auguste de Staël et du groupe de Coppet. Le dernier est davantage tributaire de la personnalité des littérateurs français qui se rendent en Allemagne dans les années 1830 , dont quelques-uns, comme J.-J. Ampère, rendirent visite à Chamisso à Berlin. À travers les difficultés de la critique française à pénétrer le sens de son ouvre la plus populaire, le Peter Schlemihl, apparaissent ses réticences face au romantisme allemand. R.-M. Pille confirme ici ce qu'on savait déjà (cf. les travaux de Jean Bollack, de Michel Espagne et de Michaël Werner). La France de la première moitié du $\mathrm{XIX}^{\mathrm{e}}$ siècle, en dépit de la valeur de ses intermédiaires littéraires, s'efforce davantage d'adapter les œuvres allemandes au goût français que de les rendre accessibles dans une traduction fidèle à un large public.

Perrine Srmon-Nahum

L'Impossible Semblable. Regards sur trois siècles de relations littéraires francoallemandes. Sous la dir. de Stéphane Michaud. Paris, CDU et SEDES réunis, 1991. $15,9 \times 24,212 \mathrm{p}$.

Pour quiconque n'est pas de formation comparatiste mais, par métier et recherche, est amené à «comparer » deux cultures, deux pays, deux littératures, l'ensemble des communications réunies ici constitue un intéressant rappel de la richesse d'une discipline qui, en France, encore aujourd'hui, n'a pas acquis vraiment la place qui lui revient. Mais c'est aussi une introduction à une réflexion sur la nature et le rôle dévolus à cette même discipline comparatiste, réflexion parfois restée entre les lignes mais qui n'en demeure pas moins posée au lecteur.

L'option chronologique retenue permet de brosser un vaste tableau contrasté du dialogue des deux cultures entre 1750 et 1950 au rythme d'une alternance particulièrement évidente dans les premières contributions. $H$. Duranton, analysant la fortune de la Bibliothèque germanique dans la première moitié du $\mathrm{xvII}^{e}$ siècle, restitue un dialogue franco-allemand très particulier marquant le passage de la République des Lettres à l'Europe des Lumières, mouvement «transnational » certes, mais qui reste le fruit d'une élite pratiquant le latin et d'un groupe spécifique, le "Refuge huguenot». Avec la communication de H. Stenzel sur «La Genèse du classicisme » on se trouve au cour des études comparatistes et de leur problématique. Certes, l'idé que le classicisme allemand comme le classicisme français sont, chacun à leur manière, « une mise à distance du politique » est séduisante, mais trai- 
ter de façon similaire l'effet de la Fronde sur le classicisme français et celui de la Révolution française sur le classicisme allemand, faire du refoulement le ressort tant en France qu'en Allemagne - à plus d'un siècle de distance - de l'écriture classique n'est-ce pas finalement, loin de dégager des structures formelles communes, réduire des facteurs socio-culturels très divers au profit d'une constante qui serait le refus de l'histoire: "Une des fonctions essentielles du concept de classicisme consiste à neutraliser, à pallier et à surmonter la réflexion critique d'une conscience de crise » (p. 40) ? Avec l'analyse que G. Rémi consacre aux textes de E. M. Arndt, témoin de l'ère napoléonienne en Allemagne, on aborde un autre aspect de la démarche comparatiste, celle de l'analyse philologique des textes, des mots et des stéréotypes, domaine particulièrement riche où l'apport du chant populaire allemand dans la volonté d' « enflammer » plutôt que de « convaincre» est fondamentale.

Le temps, celui figé de la métaphore révolutionnaire et celui de l'action dans une évolution historique dont l'Allemagne de Büchner n'est pas exclue, est au cœur de l'analyse de La Mort de Danton de Büchner proposée par R. M. Marcel qui fait aussi une large place aux diverses variations sur le même thème - de Hugo à Wajda, de Carpentier à Yourcenar (p. 77) -, au détriment peut-être de la genèse de son transfert et de sa transposition. La communication de S. Michaud, « Nietzsche au carrefour des relations franco-allemandes », annonce clairement le propos. Limitée à une période précise et brève dans la vie de Nietzsche, c'est à travers les lectures, les emprunts, voire les néologismes plus ou moins voulus, l'exemple étonnant d'une perméabilité entre les deux cultures au niveau d'un langage emprunté à l'autre, afin d'être plus critique envers les siens. Les textes suivants relèvent parfois du style « $X$ et l'Allemagne » dont on pouvait penser que les progrès faits dans le domaine des études comparatistes le rendait un peu anachronique. On apprend certes beaucoup sur le regard porté par Zola sur l'Allemagne dans l'étude que lui consacre A. Court mais on ne saisit pas toujours pourquoi l'Allemagne se réduit à ce moment précis à un simple « objet d'étude ». Faisant de Gide « un disciple français de Goethe » (p. 124), G. Favier retrace à la fois une «vraie rencontre » francoallemande à laquelle contribue une fois de plus la lecture de Nietzsche et la «compréhension congéniale» de Gide pour la foi goethéenne en l'acte d'écrire (p. 124).

Il est toutefois significatif que, plus on avance dans le $\mathrm{xx}^{\mathrm{e}}$ siècle, plus l'alternance qui présidait à la structure du recueil s'efface pour disparaitre totalement dans les années trente. L'équilibre de ce qui se voulait dialogue en est dangereusement rompu. L'Allemagne est certes bien présente sous les regards souvent critiques et lucides d'un Giraudoux (J. Sessa), d'un Romain Rolland (B. Yon) ou d'un Roland Dorgelès (A. Zotos) mais on peut regretter l'absence du regard de l'autre sur la France - Jünger, Sieburg ou, à un tout autre titre, H. Mann, W. Benjamin et bien d'autres. On peut aussi regretter que l'analyse des revues se réduise au seul exemple cité plus haut de la Bibliothèque germanique. Une comparaison entre la Neue Rundschau et la NRF aurait été pour le « dialogue/non-dialogue » des années trente d'un intérêt certain.

La tendance s'inverse avec les dernières communications. L'analyse que G. Pinkernell consacre à l'accueil plus que divergent fait au « Rhinoceros » de Ionesco en France et en Allemagne dans les années cinquante illustre un dialogue impossible 
jusqu'à la caricature. On retiendra aussi le constat plutôt amer de E. Reichel, «La France vue de l'étranger : un tournant? », qui traite de la fin d'une entité qui avait nom culture française. Le constat est impitoyable mais ne serait-il pas semblable sur d'autres bases - pour la culture allemande? Et n'est-ce pas, en fait, le concept même de culture qui se trouve ici remis en question? Une comparaison plus poussée sur ce point aurait été sans doute fructueuse. Le recueil s'achève sur une note plus positive avec l'essai de H. Thoma cherchant à définir les formes d'une «communication interculturelle"

Le titre du recueil, si paradoxal qu'il puisse paraître, traduit bien les richesses et les ambiguïtés du dialogue franco-allemand. La chronologie fait ressortir la diversité des moments charnières sur lesquels il repose, l'alternance souligne la disparité des regards portés sur la culture, la littérature, voire les mentalités de l'autre. Dans ce jeu de la réflexion réciproque, on aurait aimé voir apparaître au terme de la comparaison des structures formelles communes et s'affirmer plus fortement une cohérence au niveau de la définition, voire de la redéfinition des concepts. Dans ce dialogue alterné, chacun des partenaires reste sur son terrain et sur la défensive et une simple mise en parallèle des éléments (comme des évolutions) culturels ne facilite pas toujours le vrai dialogue. La discipline comparatiste trouve là cependant une occasion de montrer la multiplicité de ses démarches, même si l'on peut regretter qu'elle ne se risque pas à entrecroiser plus fermement regards, approches et discours et à créer ainsi une sorte de supradialogue, sans doute pas totalement « impossible». 